\title{
Automated Parallel Synthesis of N-Alkylated- $\alpha$-Amino Methyl Esters in Gram Quantities
}

\author{
Sylvie Chamoin*, Hans-Jörg Roth, Carsten Borek, Aline Jary, and Hugues Maillot
}

\begin{abstract}
N}$-alkylated- $\alpha$-amino acids and methyl esters are a special class of building blocks used for the production of combinatorial libraries. They have two reactive groups for their incorporation into chemical scaffolds and they bear on their 3-atom backbone two residues which contribute to the diversity of a library. The work contained herein describes the methodology to synthesize $\mathrm{N}$-alkylated- $\alpha$-amino acids and methyl esters in a parallel and automated fashion. The aim was the preparation of a series of these building blocks in gram quantities. Furthermore, the reported method tolerates that the $\mathrm{N}$-residues as well as the $\alpha-\mathrm{C}$ residues bear a wide range of pharmacologically relevant functional groups, including ones with acid-labile protecting groups. Following a reductive alkylation procedure, using $\mathrm{NaBH}_{4}$ as reducing reagent, 14 different $\alpha$-amino methyl esters have been combined with nine different aldehydes. The products were isolated in satisfying purities and moderate to good yields. For the demanding extraction procedure (volumes of $150 \mathrm{ml}$ ), a recently developed automated system has been successfully applied and is reported here for the first time.
\end{abstract}

Keywords: N-Alkylated- $\alpha$-amino acids · N-Alkylated- $\alpha$-amino methyl esters · Automation ·

Parallel synthesis $\cdot$ Reductive alkylation

\section{Introduction}

\subsection{The Special Character of Amino Acid Building Blocks}

Chemical libraries usually consist of a central scaffold with residues attached to this scaffold at different positions in order to obtain many diverse compounds. These residues are introduced as building blocks which consist of a reactive function and an unreactive residue directly attached to it. The reactive function is used for the attachment of the residue to the core structure of the library compounds or for its incorporation into the scaffolds. The residues of the building blocks are responsible for the diversity of the library at the different vari-

\footnotetext{
${ }^{*}$ Correspondence: Dr. S. Chamoin Novartis Pharma AG Central Technologies NIBR Basel Combinatorial Chemistry Unit WSJ-507-7.12

$\mathrm{CH}-4002$ Base

Tel. + 41613247186

Fax: + 41613244236

E-Mail: sylvie.chamoin@pharma.novartis.com
}

ation sites of the scaffold. The most frequent building blocks used for the preparation of combinatorial libraries are amines, aldehydes, acids and isocyanates. They typically consist of one reactive group. In contrast to this, amino acids have two reactive groups (an amino and a carboxylic group) and are typically incorporated into the scaffolds. Only in rare cases, amino acids are attached to small organic molecule scaffolds. The difference between building blocks with one reactive group and amino acids bearing two reactive groups is therefore the contribution of the latter to the build-up of the scaffold. Hence, amino acid building blocks introduce simultaneously with their side chains the diversity to a library and with their 3-atom backbone a sub-unit of the core structure (Scheme 1).

Amino acids are the only class of building blocks which bear a wide range of functional groups and are commercially available in two enantiomeric forms. The effort to develop the chemistry for the preparation of a given library can therefore be applied twice in exactly the same way but generating the double number of compounds, which are in a chiral environment different to each other.
To our surprise, a search of the recent literature revealed only a few examples in the field of non-peptidic and non-peptidometic libraries, where amino acids have been used as building blocks, mainly to build-up cyclic scaffolds. [1-14]

\subsection{N-Alkylated Amino Acids as Building Blocks}

In addition to the characteristics mentioned above, $N$-alkylated amino acids bear on their 3-atom backbone two substituents. This additional position for variation renders them a class of building blocks with a high density of chemical diversity. As they allow the introduction of two variable residues with the simultaneous build up of parts of the scaffold in one step, $\mathrm{N}$-alkylated amino acids are exceptionally useful for the preparation of combinatorial libraries in solution (Scheme 2).

Many advantages favoring the preparation of libraries in solution have been mentioned in the literature. However, to our knowledge, the most important advantage has not been mentioned so far: The preparation of a library in solution following a convergent synthesis strategy allows a dramatic reduction of the number of sequen- 
Building block with one reactive group is attached to the scaffold:<smiles>[R]Oc1ccccc1CC</smiles>

Building block with one reactive group is incorporated into the scaffold:<smiles>[R]NCCCCCC</smiles>

Building block with two reactive groups, additionally builds up the scaffold:<smiles>[R]C(N)C(=O)O</smiles><smiles>Nc1ccccc1Cl</smiles><smiles>C1CCCC1</smiles>
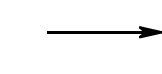

$\mathrm{R}$<smiles>[R]C1Nc2ccccc2NC1=O</smiles>

\section{Two variable residues and a part of the backbone are introduced in one chemical step:}<smiles>[R2]NC([R])C(=O)O</smiles>
$+$<smiles>Nc1ccccc1Cl</smiles><smiles>C1CCCC1</smiles>

R1<smiles>[R7][C@@H]1C(=O)Nc2ccccc2N1[R2]</smiles>

tial steps. As a consequence, libraries of higher (and not lower) structural complexity can be achieved in solution in fewer transformations than on a solid phase, where linear synthesis routes have to be applied.

Another attraction of $\mathrm{N}$-alkylated amino acids as building blocks for combinatorial libraries in the context of lead finding are the preferred pharmacologically relevant properties of the functional groups (tertiary amines and tertiary amides) which are incorporated into the scaffolds.

All this together prompted us to initiate several library projects where $\mathrm{N}$-alkylated$\alpha$-amino acids or their corresponding esters are used as building blocks, following convergent synthesis routes in solution.

Out of the recently published library preparations, only three scaffolds [7][9] contain N-alkylated amino acids as a substructure. In all cases, the amino acids were $\mathrm{N}$-alkylated via reductive alkylation on solid phase. We assumed that the relatively low appearance of this motif in libraries is due to the lack of a reliable method for the synthesis of $\mathrm{N}$-alkylated amino acids and esters in gram quantities. Only a few $\mathrm{N}$-benzyl amino methyl esters are commercially available. Therefore, we initiated a chemistry program for the investigation of the synthesis of $\mathrm{N}$-alkylated- $\alpha$-amino acids and esters with the following criteria: 1) The method should tolerate all typical side chains of natural amino acids, including the ones bearing acid labile protecting groups.

2) The $\mathrm{N}$-alkyl residues introduced via aldehydes should cover a wide range
Scheme 1. Various types of building blocks

Scheme 2. N-alkylated amino acids introduce two residues and build up the scaffold simultaneously

of pharmacologically relevant functional groups including acids, amines, alcohols, imidazoles, indoles, and pyridyls.

3) The method should allow the parallel synthesis of the desired building blocks in gram quantities.

The special case of the synthesis of $\mathrm{N}$-methyl- $\alpha$-amino methyl esters, which was also intensively investigated by us, is excluded from this publication and will be published elsewhere [15].

\subsection{Starting Point}

Various approaches to N-alkylated$\alpha$-amino acids and $\mathrm{N}$-alkylated- $\alpha$-amino methyl esters have been described in the literature. Among the methods reported, reductive alkylation plays an important role for the preparation of N-benzyl derivatives. 
Various reducing agents have been employed such as $\mathrm{NaBH}_{4}$ or $\mathrm{NaCNBH}_{3}$. Quitt, Hellerbach, and Vogler [16] published in 1963 a three-step process for the preparation of $\mathrm{N}$-methyl- $\alpha$-amino acids in which the first step involves the reductive alkylation of $\alpha$-amino acids with benzaldehyde and $\mathrm{NaBH}_{4}$ in aqueous sodium hydroxide. In 1985, Rapoport and co-workers [17] reported the preparation of N-benzyl threonine methyl ester in 57\% yield after column chromatography by reductive alkylation with benzaldehyde and $\mathrm{NaCNBH}_{3}$ in glacial acetic acid and DCM. In 1990, Thompson and co-workers [18] slightly modified the conditions used by Rapoport and coworkers to prepare $\mathrm{N}$-benzyl serine methyl ester. They used $\mathrm{NaBH}_{4}$ under basic conditions (triethylamine, benzaldehyde) and obtained the products in good yield and purity without column chromatography. In 1997, in their synthetic approach on solid phase to 1,2,4,7-tetrasubstituted perhydro1,4-diazepine-2,5-diones, Houghten and co-workers [19] carried out the reductive alkylation of resin-bound aspartic acid with four different benzaldehyde derivatives in the presence of $\mathrm{NaCNBH}_{3}$ in DMF containing $1 \% \mathrm{AcOH}$. Other approaches to $\mathrm{N}$-alkyl- $\alpha$-amino acids have been reported in the literature. These include the formation in good overall yields of Fmoc-protected $\mathrm{N}$-alkyl- $\alpha$-amino acids by a two-step strategy reported by Freidinger and coworkers [20] in 1983. In the first step oxazolidinones are formed by the acid-catalyzed condensation of various Fmoc-protected amino acids (including protected lysine and histidine) with aldehydes (cyclohexane carboxaldehyde, acetaldehyde and phenyl acetaldehyde) in the presence of $p$-toluenesulfonic acid in benzene at reflux. In the second step, the oxazolidinones are reduced with triethylsilane and trifluoroacetic acid to the $\mathrm{N}$-alkyl derivatives. Other routes to $\mathrm{N}$-alkyl- $\alpha$-amino esters involved the alkylation of sulfonamides via a Mitsunobu reaction, such as 2,2,5,7,8-pentamethylchroman-6-sulfonyl amino esters [21] or 4-dinitrobenzenesulfonyl phenylalanine methyl ester [22], in which the sulfonyl groups act as protecting groups. Another approach is the alkylation of N-unprotected $\alpha$-amino methyl esters by lithium hydroxide promoted alkylation of $\alpha$-amino methyl esters using activated alkyl bromides as reported in 2002 by Cho and Kim [23]. They tested a wide range of amino esters, however the applied selection of alkyl bromides was limited to activated alkyl groups including propargyl, benzyl, 2-nitrobenzyl and methoxycarbomethyl groups. This method involved a purification step by column chromatography as in some cases the formation of dialkylated product was reported.

In all the previously described approaches (one-, two- or three-step reaction process), an important feature is the limited diversity of the amino acids employed and/or of the alkyl side chains introduced. In the course of our experiments, Verardo and co-workers [24] broadened the spectrum of alkyl chains by publishing the preparation of $35 \mathrm{~N}$-alkylated- $\alpha$-amino acids and methyl esters by a reductive alkylation reaction using eight different amino acids (Asn, Asp, Gly, His, Leu, Met, Phe, Trp, Tyr) and four different aldehydes ( $\mathrm{R}=\mathrm{Et}$, $\mathrm{Pr}, t \mathrm{Bu}, \mathrm{Ph})$ and acetone in the presence of sodium borohydride.

\section{Results}

\subsection{Preliminary Studies (Non Parallel)}

We aimed to prepare both $\mathrm{N}$-alkyl- $\alpha$ amino acids and $\mathrm{N}$-alkyl- $\alpha$-amino methyl esters. We first considered the synthesis of the acid derivatives using the reductive alkylation reaction in the presence of benzaldehyde and $\mathrm{NaCNBH}_{3}$. Even after variation of the reaction conditions, we could not achieve satisfactory results. We switched the reducing agent to $\mathrm{NaBH}_{4}$ and followed the procedure of Quitt et al. [16] describing the synthesis of N-benzyl amino acids. We screened a variety of amino acids $(\mathrm{H}-$ Ala-OH, H-Asp(OtBu)-OH, H-Phe-OH, H$\mathrm{Dab}$ (Boc)-OH, H-Ser( $t \mathrm{Bu})-\mathrm{OH}, \mathrm{H}-\mathrm{Thr}(t \mathrm{Bu})-$ $\mathrm{OH}, \mathrm{H}-\mathrm{Trp}(\mathrm{Boc})-\mathrm{OH}, \mathrm{H}-\mathrm{Tyr}(\mathrm{tBu})-\mathrm{OH}, \mathrm{H}-$ Val-OH). Typically, benzaldehyde (1 equiv.) was added at room temperature to a solution of amino acid in aqueous sodium hydroxide $2 \mathrm{M}$. After $2 \mathrm{~h}$, a time sufficient to form the imine intermediate, the reaction mixture was cooled to $0{ }^{\circ} \mathrm{C}$ and solid $\mathrm{NaBH}_{4}$ (0.3 equiv.) was slowly added. After aqueous work-up, the desired N-benzyl derivatives were filtered off the reaction mixture. Excellent purities $>95 \%$ were obtained without further purification with the exception of tryptophan, where the desired compound was contaminated with $20 \%$ starting material. We then extended the scope of the method by testing aldehydes that have, to our knowledge, never been involved in this type of reaction. We chose phenylalanine as a model substrate for its easy HPLC detection. The reductive alkylation was carried out in the presence of $\mathrm{NaBH}_{4}$ with pyridine-3- and -4-carboxaldehyde, 2-methylbutyraldehyde, 4-dimethylamino-benzaldehyde, 1-methylindole-2-carboxaldehyde. On the basis of these experiments, we observed that excellent purities could be achieved, however the yields were somehow moderate, depending on the precipitation of the products after aqueous work-up and subsequent neutralization.

The automation of this process would allow the formation of a wide range of diverse $\mathrm{N}$-alkylated- $\alpha$-amino acids in good purities. The yields obtained, and the difficulty to automate this type of filtration, indicate that the efficiency of the process would be questionable. The access to the $\mathrm{N}$-alkylated- $\alpha$-amino esters would (in this case) rely on an esterification reaction of the corresponding acids (Scheme 3 ).

We next focused on an alternative approach to $\mathrm{N}$-alkylated- $\alpha$-amino methyl esters and $\mathrm{N}$-alkylated- $\alpha$-amino acids. We investigated the reductive alkylation of $\alpha$ amino methyl esters and their subsequent hydrolysis to $\mathrm{N}$-alkylated- $\alpha$-amino acids, expecting that hydrolysis of esters should be simpler than ester formation.

For the synthesis of $\mathrm{N}$-alkylated- $\alpha$ amino methyl esters we extended the scope of the procedure of Thompson et al. [18] already mentioned. We first performed the benzylation of various $\alpha$-amino methyl ester hydrochlorides ( $\mathrm{H}-\mathrm{Ala}-\mathrm{OMe} \cdot \mathrm{HCl}, \mathrm{H}-$ $\mathrm{Asp}(\mathrm{O} t \mathrm{Bu})-\mathrm{OMe} \cdot \mathrm{HCl}, \mathrm{H}-\mathrm{Glu}(\mathrm{O} t \mathrm{Bu})-\mathrm{OMe}$ $\mathrm{HCl}, \mathrm{H}-\mathrm{Gly}-\mathrm{OMe} \cdot \mathrm{HCl}, \mathrm{H}-\mathrm{Leu}-\mathrm{OMe} \cdot \mathrm{HCl}$, $\mathrm{H}$-Lys(Boc)-OMe $\mathrm{HCl}$, H-Phe-OMe $\mathrm{HCl}$, $\mathrm{H}-\mathrm{Phg}-\mathrm{OMe} \cdot \mathrm{HCl}, \quad \mathrm{H}-\mathrm{Ser}(\mathrm{Bu})-\mathrm{OMe} \cdot \mathrm{HCl}$, $\mathrm{H}-\mathrm{Thr}(t \mathrm{Bu})-\mathrm{OMe} \cdot \mathrm{HCl}, \quad \mathrm{H}-\mathrm{Tyr}(t \mathrm{Bu})-\mathrm{OMe}$ $\mathrm{HCl}, \mathrm{H}-\mathrm{Val}-\mathrm{OMe} \cdot \mathrm{HCl}, \mathrm{H}-3,4-(\mathrm{OMe})_{2}$-Phe$\mathrm{OMe} \cdot \mathrm{HCl})$ with benzaldehyde in the presence of triethylamine and sodium borohydride in methanol. The purities were excellent $(>95 \%)$ with the exception of N-BzlGly-OMe (70\% purity). The average yields were good, in the range of $75 \%$ (better

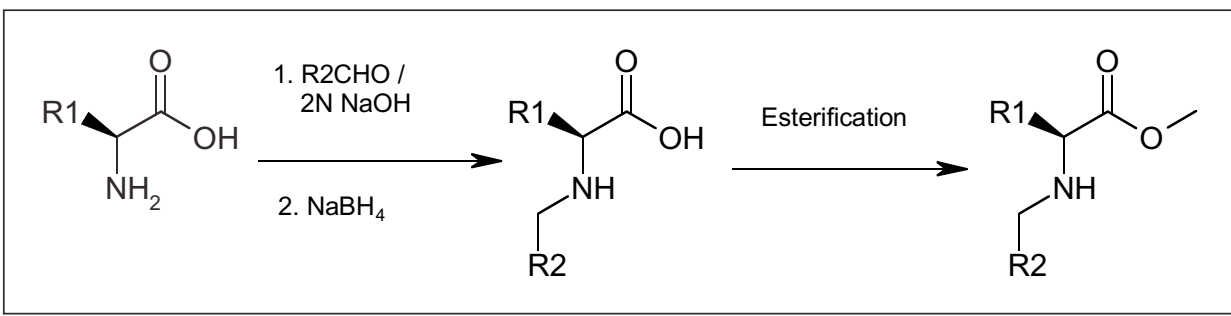

Scheme 3. Route to $\mathrm{N}$-alkylated- $\alpha$-amino methyl esters via $N$-alkylated- $\alpha$-amino acids 
than the ones obtained with the procedure of Quitt and co-workers for the N-benzylation of $\alpha$-amino acids). We also screened this reductive alkylation protocol for other aldehydes. The reaction between H-Phe$\mathrm{OMe} \cdot \mathrm{HCl}$ proceeded smoothly with pyridine3- and -4-carboxaldehyde, thiophene-2-carboxaldehyde, anisaldehyde, 2-methylbutyraldehyde, 4-dimethyl-amino-benzaldehyde, 1-methylindole-2-carboxaldehyde affording the corresponding products in high purities and good yields. With this protocol in hand, we examined the access to $\mathrm{N}$-alkyl- $\alpha$ amino acids. N-Alkyl- $\alpha$-amino methyl esters were hydrolysed in the presence of $5 \mathrm{~N} \mathrm{LiOH}$ in dioxane to afford $\mathrm{N}$-alkyl- $\alpha$ amino acids in $90 \%$ yield (Scheme 4 ).

On the basis of these preliminary studies, we decided to develop a parallel and automated preparation of a large series of $\mathrm{N}$-alkyl- $\alpha$-amino methyl esters in multiple gram quantities.

\subsection{Parallel Preparation of $126 \mathrm{~N}$ - Alkylated- $\alpha$-Amino Methyl Esters}

If we segment the process of chemical reactions into the sub fields of a) accomplishment of reactions b) work-up of reactions and c) purification of crude products, only a) and c) have become broad areas for automated processes. Sophisticated devices, called synthesizers, for the automated addition of reagents to reactor vessels under technically demanding conditions (e.g. inert gas, low temperatures) have become commercially available as well as automated systems for purification. Whilst high-throughput LC-MS systems have conquered their consolidated place in the field of library purification, the synthesizers have not demonstrated their general usefulness. This might mainly be due to the fact, that the function of a 'synthesizer' in organic chemistry can be - once the addition of reagents is finished - essentially reduced to parallel stirring and heating. Even cooling is a function that is rarely required for the production of combinatorial libraries. In contrast to these rudimentary requirements, the principal part of a 'synthesizer' consists indeed of the technically demanding capability to add automatically solvents and reagents. Because adding reagents and solvents to vessels in order to start chemical reactions is such a small effort, compared with the preparation of the experiments, the work-up and the purification, it is a step which is - in our eyes - not worth automating, even for larger libraries. However, it is worth mentioning that moregeneric automated liquid handling systems play very well an important role in all process steps of combinatorial chemistry. They have demonstrated their usefulness

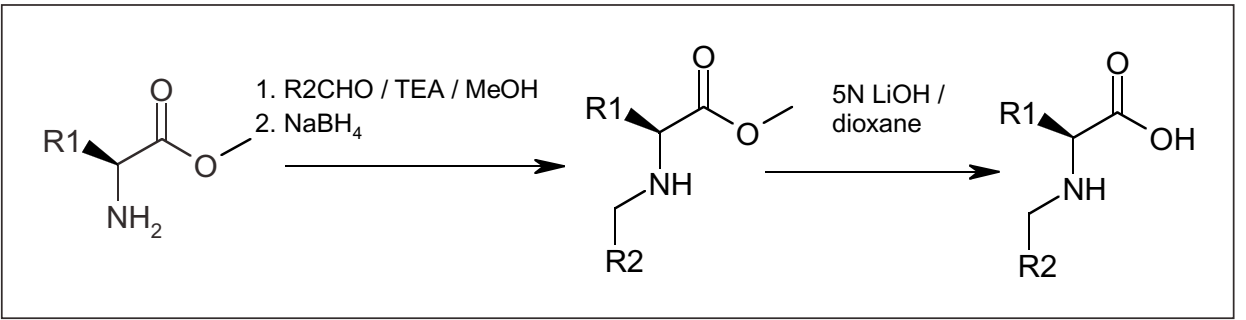

Scheme 4. Route to N-alkylated- $\alpha$-amino acids via N-alkylated- $\alpha$-amino methyl esters for the distribution of stock solutions and nonsensitive reagents or for the generation of copies of product plates.

However, in contrast to the step of starting a reaction by adding reagents, the work-up of reactions, usually liquid-liquid extractions, can become dramatically time consuming as soon as the number of reactions increases. It is therefore the sub field b) (work-up of reactions) where a definite need for automation is obvious. Surprisingly, there is only one major provider (Mettler-Toledo) of commercial systems Because our needs for the synthesis of building blocks, starting materials or intermediates are in the range of grams, the maximum extraction volume of $90 \mathrm{ml}$ of the Allex ${ }^{\mathrm{TM}}$ system was insufficient for us.

Together with Dr. T. Zoller from Ciba SC and the Hamilton company, we develdedicated to multiple automated extraction. oped a system that allows the parallel and automated extraction of volumes up to $150 \mathrm{ml}$ (Fig. 1). Two shakers, independently controlled from each other, can host together 96 tubes of 50 or $100 \mathrm{ml}$ or 48 tubes of $150 \mathrm{ml}$ volume. In order to have a complete mixing of the aqueous organic phases, a vortexing speed of up to $600 \mathrm{rpm}$ is possible. Special fittings at the edges of the holes of the racks hold the tubes tightly during such a fast vortexing. The shakers are inserted in the desk of the liquid handling system and placed on independent aluminum tables, which have been fixed on the lab floor. This guarantees that no resonance is transferred from the shakers to the liquid handling system. Syringes of $25 \mathrm{ml}$ volume manage the solvent delivery and the aspiration of aqueous or organic phases. The software allows rather complex extraction procedures to be programmed.

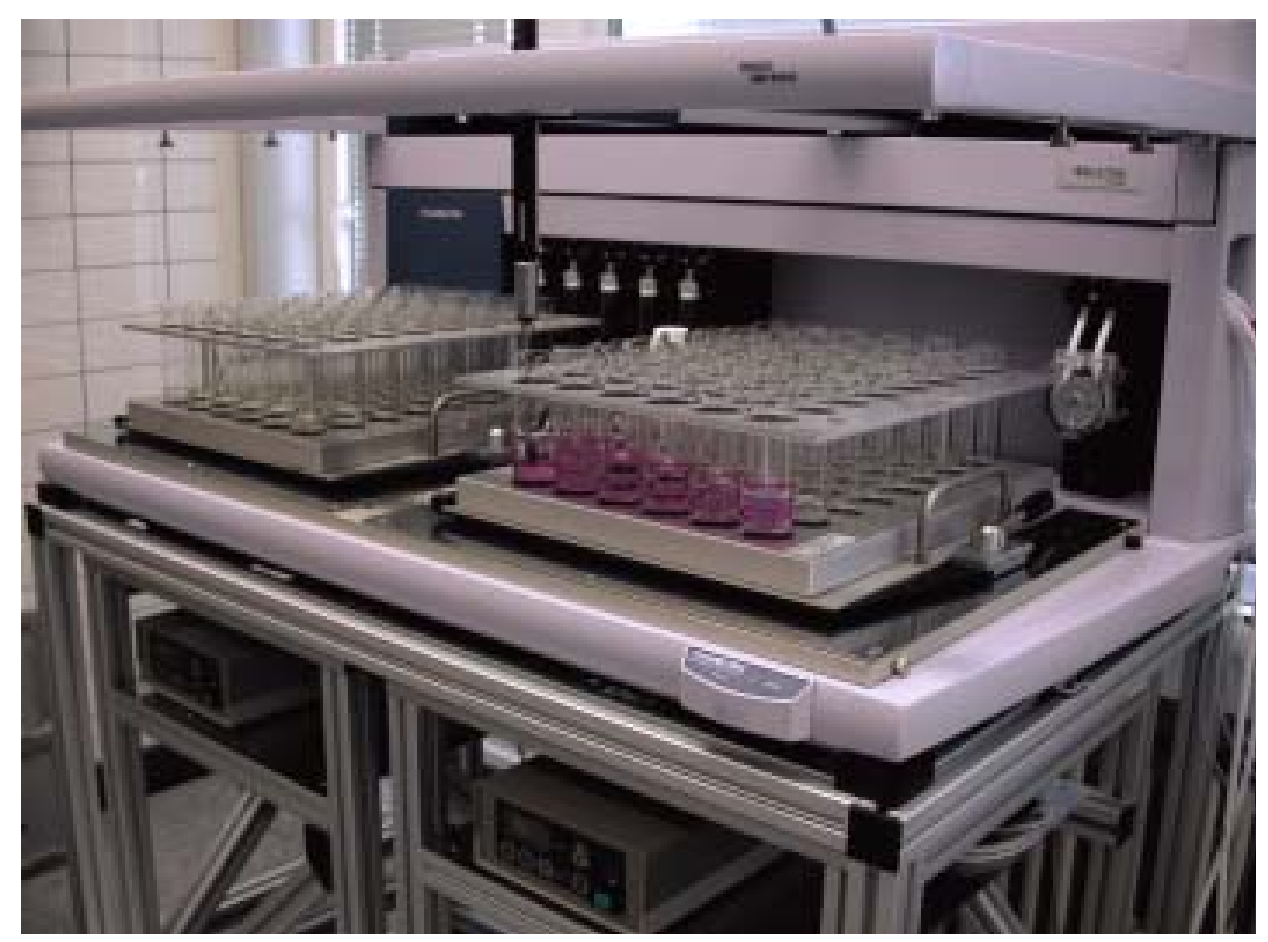

Fig. 1: Hamilton twin extraction station with two independent shakers integrated 
Table 1. Automated preparation of a series of $N$-alkyl- $\alpha$-amino methyl esters

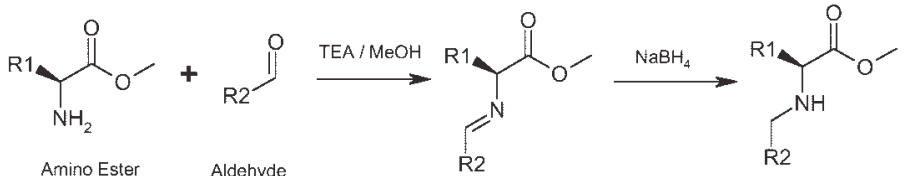

\begin{tabular}{|c|c|c|c|c|c|c|c|c|c|c|c|}
\hline Amino Ester & Aldehyde 1 & Purity $^{a}$ & Yield $^{\mathrm{b}}$ & Amino Ester & Aldehyde 2 & Purity ${ }^{a}$ & Yield $^{b}$ & Amino Ester & Aldehyde 3 & Purity $^{a}$ & Yield $^{b}$ \\
\hline Ala & & $>95 \%$ & $>95 \%$ & Ala & & $47 \%$ & $18 \%$ & Ala & & $95 \%$ & $40 \%$ \\
\hline $\mathrm{Asp}(\mathrm{O} t \mathrm{Bu})$ & & $94 \%$ & $72 \%$ & $\mathrm{Asp}(\mathrm{O} t \mathrm{Bu})$ & & $54 \%$ & $42 \%$ & $\mathrm{Asp}(\mathrm{O} t \mathrm{Bu})$ & & $44 \%$ & $37 \%$ \\
\hline Gly & & $87 \%$ & $63 \%$ & Gly & & $49 \%$ & $6 \%$ & Gly & & $52 \%$ & $13 \%$ \\
\hline His(Bn) & & $52 \%$ & $43 \%$ & $\mathrm{His}(\mathrm{Bn})$ & & $60 \%$ & $9 \%$ & $\mathrm{His}(\mathrm{Bn})$ & & $74 \%$ & $22 \%$ \\
\hline Leu & & $83 \%$ & $28 \%$ & Leu & & $69 \%$ & $47 \%$ & Leu & & $82 \%$ & $48 \%$ \\
\hline Lys(Boc) & & $92 \%$ & $70 \%$ & Lys(Boc) & & $87 \%$ & $78 \%$ & Lys(Boc) & & $88 \%$ & $86 \%$ \\
\hline Met & & $61 \%$ & $34 \%$ & Met & & $53 \%$ & $20 \%$ & Met & & $70 \%$ & $39 \%$ \\
\hline Phe & & $90 \%$ & $50 \%$ & Phe & & $>95 \%$ & $>95 \%$ & Phe & & $>95 \%$ & $>95 \%$ \\
\hline Phg & & $95 \%$ & $59 \%$ & Phg & & $80 \%$ & $56 \%$ & Phg & & $75 \%$ & $37 \%$ \\
\hline $\operatorname{Ser}(t \mathrm{Bu})$ & & $90 \%$ & $69 \%$ & $\operatorname{Ser}(t \mathrm{Bu})$ & & $90 \%$ & $79 \%$ & $\operatorname{Ser}(t \mathrm{Bu})$ & & $95 \%$ & $74 \%$ \\
\hline $\operatorname{Thr}(t \mathrm{Bu})$ & & $82 \%$ & $38 \%$ & $\operatorname{Thr}(t \mathrm{Bu})$ & & $56 \%$ & $33 \%$ & $\operatorname{Thr}(t \mathrm{Bu})$ & & $80 \%$ & $49 \%$ \\
\hline $\operatorname{Tyr}(t \mathrm{Bu})$ & & $50 \%$ & $7 \%$ & $\operatorname{Tyr}(t \mathrm{Bu})$ & & $90 \%$ & $84 \%$ & $\operatorname{Tyr}(t \mathrm{Bu})$ & & $95 \%$ & $65 \%$ \\
\hline Val & & $>95 \%$ & $60 \%$ & Val & & $95 \%$ & $88 \%$ & Val & & $>95 \%$ & $72 \%$ \\
\hline $3,4-(\mathrm{OMe})_{2}$-Phe & & $69 \%$ & $70 \%$ & $3,4-(\mathrm{OMe})_{2}$-Phe & & $74 \%$ & $42 \%$ & $3,4-(\mathrm{OMe})_{2}$-Phe & & $58 \%$ & $32 \%$ \\
\hline Amino Ester & Aldehyde 4 & Purity $^{a}$ & Yield $^{b}$ & Amino Ester & Aldehyde 5 & Purity $^{\mathrm{a}}$ & Yield $^{\mathrm{b}}$ & Amino Ester & Aldehyde 6 & Purity $^{\mathrm{a}}$ & Yield $^{\mathrm{b}}$ \\
\hline Ala & & $85 \%$ & $84 \%$ & Ala & & $41 \%$ & $19 \%$ & Ala & & $80 \%$ & $51 \%$ \\
\hline $\mathrm{Asp}(\mathrm{O} t \mathrm{Bu})$ & & $77 \%$ & $5 \%$ & $\mathrm{Asp}(\mathrm{O} t \mathrm{Bu})$ & & $75 \%$ & $77 \%$ & $\mathrm{Asp}(\mathrm{O} t \mathrm{Bu})$ & & $73 \%$ & $52 \%$ \\
\hline Gly & & $0 \%$ & $0 \%$ & Gly & & $>95 \%$ & $81 \%$ & Gly & & $67 \%$ & $29 \%$ \\
\hline $\mathrm{His}(\mathrm{Bn})$ & & $60 \%$ & $35 \%$ & $\mathrm{His}(\mathrm{Bn})$ & & $80 \%$ & $76 \%$ & $\mathrm{His}(\mathrm{Bn})$ & & $51 \%$ & $55 \%$ \\
\hline Leu & & $33 \%$ & $2 \%$ & Leu & il & $59 \%$ & $57 \%$ & Leu & & $73 \%$ & $63 \%$ \\
\hline Lys(Boc) & & $92 \%$ & $8 \%$ & Lys(Boc) & & $94 \%$ & $>95 \%$ & Lys(Boc) & & $84 \%$ & $83 \%$ \\
\hline Met & & $42 \%$ & $17 \%$ & Met & & $0 \%$ & $0 \%$ & Met & & $51 \%$ & $39 \%$ \\
\hline Phe & & $80 \%$ & $39 \%$ & Phe & & $90 \%$ & $91 \%$ & Phe & & $90 \%$ & $37 \%$ \\
\hline Phg & & $0 \%$ & $0 \%$ & Phg & & $>95 \%$ & $28 \%$ & Phg & & $90 \%$ & $63 \%$ \\
\hline $\operatorname{Ser}(t \mathrm{Bu})$ & & $>95 \%$ & $67 \%$ & $\operatorname{Ser}(t \mathrm{Bu})$ & & $90 \%$ & $94 \%$ & $\operatorname{Ser}(t \mathrm{Bu})$ & & $75 \%$ & $44 \%$ \\
\hline $\operatorname{Thr}(t \mathrm{Bu})$ & & $75 \%$ & $22 \%$ & $\operatorname{Thr}(t \mathrm{Bu})$ & & $45 \%$ & $41 \%$ & $\operatorname{Thr}(t \mathrm{Bu})$ & & $79 \%$ & $78 \%$ \\
\hline $\operatorname{Tyr}(t \mathrm{Bu})$ & & $50 \%$ & $3 \%$ & $\operatorname{Tyr}(t \mathrm{Bu})$ & & $90 \%$ & $>95 \%$ & $\operatorname{Tyr}(t \mathrm{Bu})$ & & $80 \%$ & $10 \%$ \\
\hline Val & & $>95 \%$ & $85 \%$ & Val & & $>95 \%$ & $>95 \%$ & Val & & $>95 \%$ & $26 \%$ \\
\hline 3,4-(OMe $)_{2}$-Phe & & $51 \%$ & $5 \%$ & 3,4-(OMe $)_{2}-\mathrm{Phe}$ & & $14 \%$ & $14 \%$ & 3,4-(OMe $)_{2}$-Phe & & $58 \%$ & $47 \%$ \\
\hline Amino Ester & Aldehyde 7 & Purity $^{a}$ & Yield $^{b}$ & Amino Ester & Aldehyde 8 & Purity $^{\mathrm{a}}$ & Yield $^{b}$ & Amino Ester & Aldehyde 9 & Purity $^{\mathrm{a}}$ & Yield $^{\mathrm{b}}$ \\
\hline Ala & & $0 \%$ & $0 \%$ & Ala & & $0 \%$ & $0 \%$ & Ala & & $94 \%$ & $57 \%$ \\
\hline $\operatorname{Asp}(\mathrm{O} t \mathrm{Bu})$ & & $92 \%$ & $84 \%$ & $\operatorname{Asp}(\mathrm{O} t \mathrm{Bu})$ & & $61 \%$ & $53 \%$ & $\mathrm{Asp}(\mathrm{O} t \mathrm{Bu})$ & & $90 \%$ & $34 \%$ \\
\hline Gly & & $43 \%$ & $3 \%$ & Gly & & $22 \%$ & $3 \%$ & Gly & & $53 \%$ & $25 \%$ \\
\hline His(Bn) & & $42 \%$ & $2 \%$ & $\mathrm{His}(\mathrm{Bn})$ & & $56 \%$ & $35 \%$ & $\operatorname{His}(\mathrm{Bn})$ & & $71 \%$ & $60 \%$ \\
\hline Leu & & $87 \%$ & $71 \%$ & Leu & & $62 \%$ & $35 \%$ & Leu & & $>95 \%$ & $69 \%$ \\
\hline Lys(Boc) & & $95 \%$ & $95 \%$ & Lys(Boc) & 0 & $52 \%$ & $50 \%$ & Lys(Boc) & & $89 \%$ & $70 \%$ \\
\hline Met & & $63 \%$ & $14 \%$ & Met & & $57 \%$ & $>95 \%$ & Met & & $66 \%$ & $39 \%$ \\
\hline Phe & & $85 \%$ & $50 \%$ & Phe & & $95 \%$ & $>95 \%$ & Phe & & $65 \%$ & $8 \%$ \\
\hline Phg & & $80 \%$ & $68 \%$ & Phg & & $>95 \%$ & $78 \%$ & Phg & 3uo' & $>95 \%$ & $67 \%$ \\
\hline $\operatorname{Ser}(t \mathrm{Bu})$ & & $95 \%$ & $77 \%$ & $\operatorname{Ser}(t \mathrm{Bu})$ & & $0 \%$ & $0 \%$ & $\operatorname{Ser}(t \mathrm{Bu})$ & & $93 \%$ & $76 \%$ \\
\hline $\operatorname{Thr}(t \mathrm{Bu})$ & & $88 \%$ & $85 \%$ & $\operatorname{Thr}(t \mathrm{Bu})$ & & $22 \%$ & $9 \%$ & $\operatorname{Thr}(t \mathrm{Bu})$ & & $92 \%$ & $85 \%$ \\
\hline $\operatorname{Tyr}(t \mathrm{Bu})$ & & $95 \%$ & $87 \%$ & $\operatorname{Tyr}(t \mathrm{Bu})$ & & $75 \%$ & $19 \%$ & $\operatorname{Tyr}(t \mathrm{Bu})$ & & $62 \%$ & $5 \%$ \\
\hline Val & & $>95 \%$ & $84 \%$ & Val & & $0 \%$ & $0 \%$ & Val & & $92 \%$ & $52 \%$ \\
\hline 3,4-(OMe $)_{2}$-Phe & & $70 \%$ & $11 \%$ & 3,4-(OMe $)_{2}$-Phe & & $72 \%$ & $51 \%$ & 3,4-(OMe $)_{2}$-Phe & & $93 \%$ & $61 \%$ \\
\hline
\end{tabular}

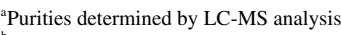

${ }^{\text {b}}$ Yield calculated as follows :
Yield = ((weight obtained / mw $) \times$ purity $) /$

number of mmols of starting amino ester
For the parallel and automated preparation of $126 \mathrm{~N}$-alkylated- $\alpha$-amino methyl esters (results summarized in the Table), we followed the procedures that we developed for the non parallel experiments described above. We selected 14 commercially available diverse $\alpha$-amino methyl esters, including acid-labile protected derivatives. We chose nine commercially available aldehydes covering a wide range of pharmacologically relevant functional groups such as aryl, pyridyl, indole, amine, imidazole, alcohol, and alkyl.
The results of the automated and parallel synthesis of all $126 \mathrm{~N}$-alkyl- $\alpha$-amino methyl esters were interpreted in terms of purities and yields. The distribution of the purities (Fig. 2) over all the synthesized compounds shows high rates of compounds with acceptable (50-75\%) and good purities $(>75 \%)$. Only $15 \%$ of the compounds were formed in purities lower than $50 \%$. From the distribution of the yields (Fig. 3), an equal distribution between satisfactory (for parallel experiments) ( $>50 \%)$ and insufficient $(<50 \%)$ yields is apparent. This fact might be explained, in the absence of an analysis of the last aqueous phases after the parallel extraction, by some more polar substances perhaps remaining in the aqueous phases. We analyzed as well the purities and the yields of the obtained compounds versus amino esters (Fig. 4 and 5) and aldehydes (Fig. 6 and 7). The best purities were observed with the methyl esters derived from Lys(Boc), Phe, Phg, Ser( $t$ Bu) and Val. In contrast, we obtained the lowest purities with the methyl esters derived from Met and 3,4-(OMe $)_{2}$-Phe. The methyl esters of 


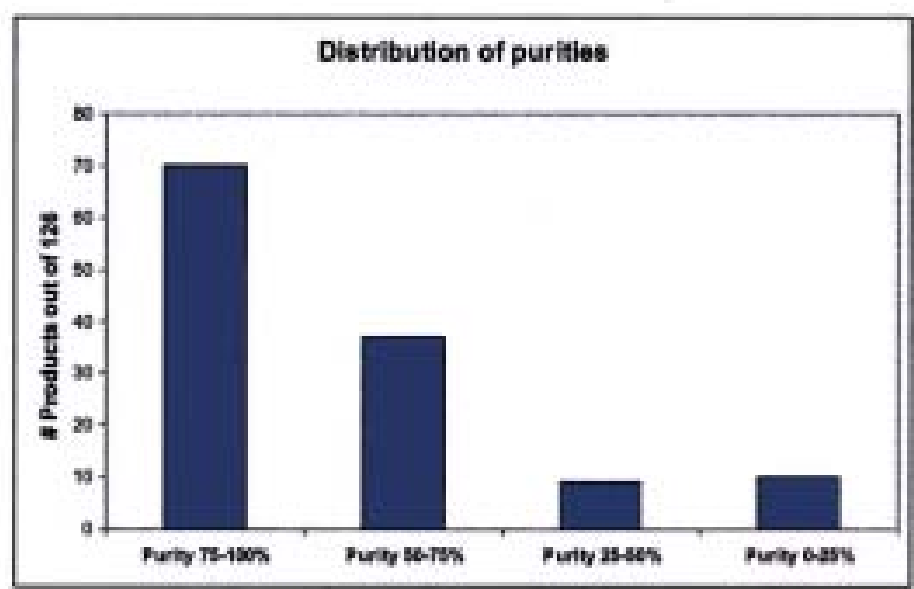

Fig. 2.

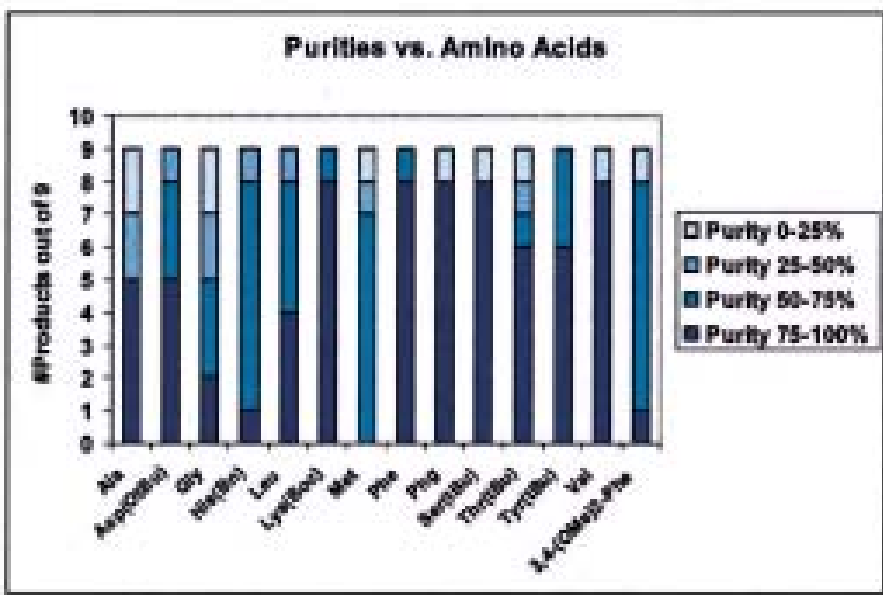

Fig. 4.

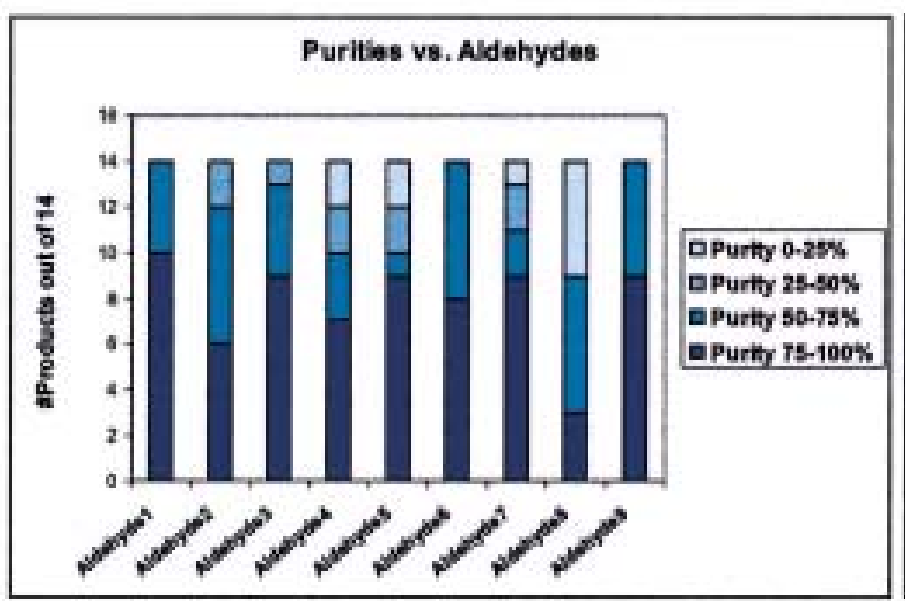

Fig. 6.

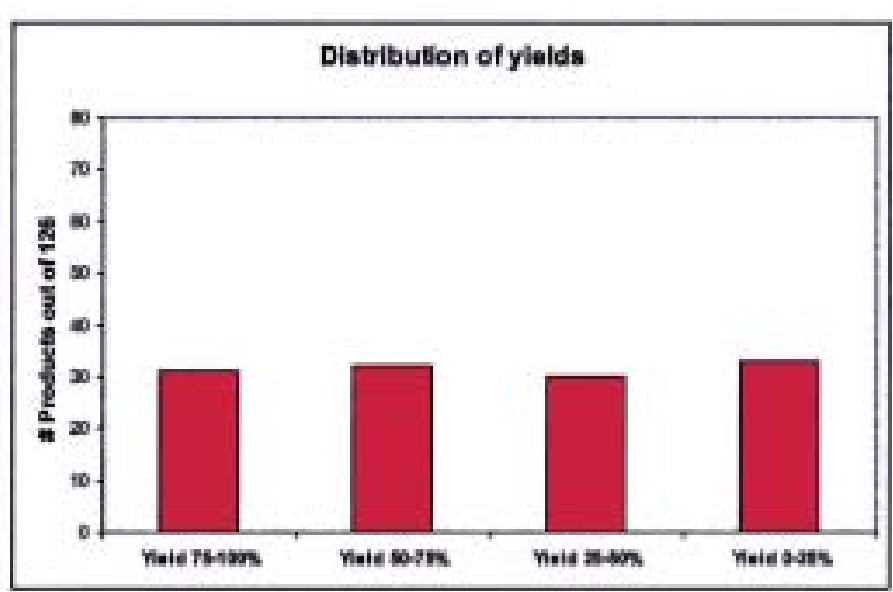

Fig. 3.

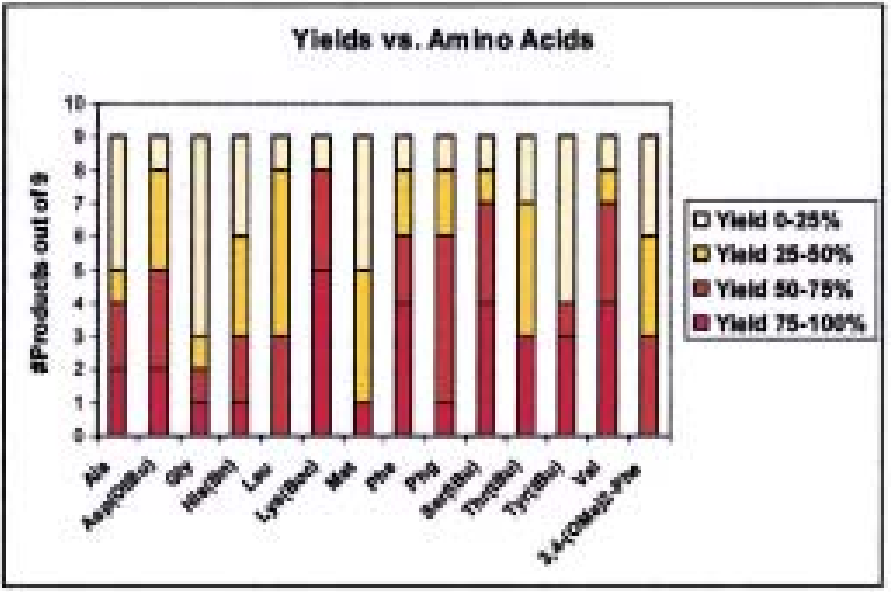

Fig. 5.

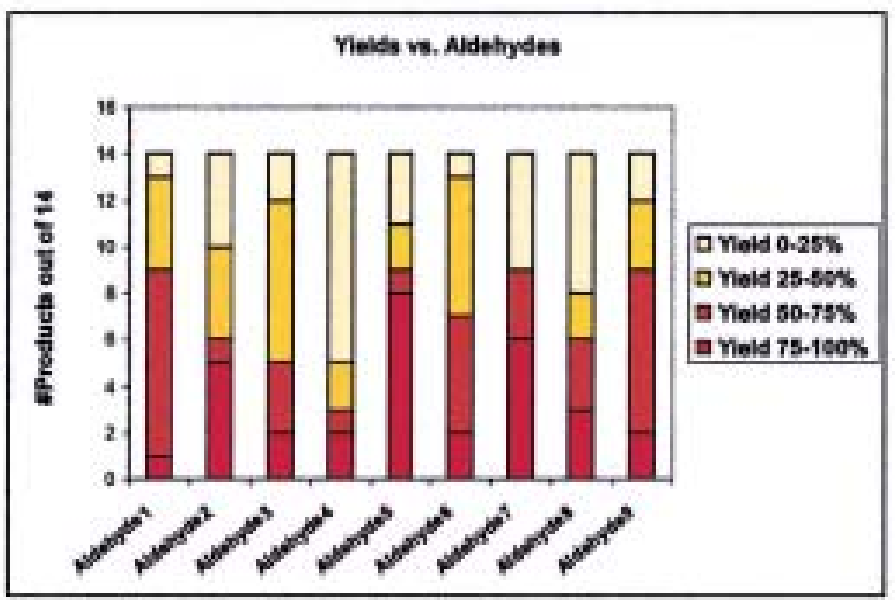

Fig. 7. 
Lys(Boc), Phe, Ser( $t \mathrm{Bu})$, Val afforded the highest yields, when they were reacted with the nine different aldehydes. Fig. 6 shows that the highest purities were achieved with benzaldehyde, 3-pyridyl-carboxaldehyde and 4-tert-butoxybenzaldehyde and the lowest purity was observed with butyraldehyde. From the results given in Fig. 7, it is apparent that dimethyl-amino benzaldehyde led to the highest yield and 1-methylindole-2-carboxaldehyde to the lowest one, when they were reacted with the 14 different amino methyl esters. Besides the inherent problems of parallelization and automation, other chemical factors such as steric hindrance and polarity of the compounds definitely had an impact on the results.

In conclusion, we developed an efficient, parallel and automated approach to a wide range of novel $\mathrm{N}$-alkylated- $\alpha$-amino methyl esters in gram quantities.

\section{Experimental}

General Remarks: The reactions were performed in $100 \mathrm{ml}$ tubes fitted in a $24 \mathrm{Var}$ iomag reaction block $(\mathrm{H}+\mathrm{P}$ Labortechnik AG). The extractions were carried out with a Hamilton Microlab 4200, modified for parallel extractions, as described above. The reaction compositions were determined using an analytical Waters HPLC system Alliance 2695 separation module. Waters reverse phase $\left(\mathrm{C}-18\right.$, Symmetry $\left.{ }^{\circledR}\right) 3 \times$ $150 \mathrm{~mm}$ radial compression module (RCM) columns were used with ACN/ $\mathrm{H}_{2} \mathrm{O} / 0.1 \%$ TFA mobile phase. ${ }^{1} \mathrm{H}$ NMR and ${ }^{13} \mathrm{C}$ NMR spectra were recorded on a Bruker-Avance-DPX-400 spectrometer in chloroform- $\mathrm{d}_{1}$ with tetramethylsilane as an internal standard. All reagents and solvents were obtained from commercial suppliers and used without further purification. All the $\alpha$-amino acids and $\alpha$-amino methyl esters were purchased from Bachem AG.

General Procedure: The amino acid methyl ester hydrochlorides $(20 \mathrm{mmol})$ were placed in $100 \mathrm{ml}$ tubes, dissolved in $30 \mathrm{ml} \mathrm{MeOH}$ and cooled to $0{ }^{\circ} \mathrm{C}$. To these solutions, triethylamine $(20 \mathrm{mmol})$ was added and the reaction mixtures were stirred for $10 \mathrm{~min}$ and allowed to warmup to room temperature. The aldehydes (24 mmol) were added and the reaction mixtures were stirred for $2 \mathrm{~h}$ at room temperature. The solutions were cooled to $0{ }^{\circ} \mathrm{C}$ and $\mathrm{NaBH}_{4}(40 \mathrm{mmol})$ was added portionwise to the reaction mixtures over a period of $30 \mathrm{~min}$. After stirring for $2 \mathrm{~h}$ at $\mathrm{T}<10{ }^{\circ} \mathrm{C}$ and $1 \mathrm{~h}$ at room temperature, the reaction mixtures were acidified with $10 \%$ aqueous $\mathrm{NaHSO}_{4}$ and ether was added. The phases were separated. The organic phases were washed with $10 \%$ aqueous $\mathrm{NaHSO}_{4}(1 \mathrm{x})$. The combined aqueous layers were carefully neutralized with solid sodium carbonate and extracted with ether (3x). The combined ether layers were dried over sodium sulfate and evaporated to afford the products.

Received: March 21, 2003

[1] 1,4-Benzodiazepinone library: B. Evans, A. Pipe, L. Clark, M. Banks, Bioorg. Med. Chem. Lett. 2001, 11, 1297.

[2] Benzodiazepine library: P.G. Wyatt, M.J. Allen, J. Chilcott, G. Hickin, N.D. Miller, P.M. Woolard, Bioorg. Med. Chem. Lett. 2001, 11, 1301

[3] Fumitremorgin analogues: A. van Loevezijn, J.D. Allen, A.H. Schinkel, G.-J. Koomen, Bioorg. Med. Chem. Lett. 2001, $11,29$.

[4] Cyclic 7-member-ring dipeptide library containing $\alpha$ - and $\beta$-aminoacids: J. Giovannoni, G. Subra, M. Amblard, J. Martinez, J. Tetrahedron Lett. 2001, 42, 5389.

[5] Diketopiperazine library: E. DiPerrotta, M. Altamura, T. Barani, S. Bindi, D. Giannotti, N.J.S. Harmat, R. Nannicini, C.A. Maggi, J. Comb. Chem. 2001, 3, 453.

[6] Diketopiperazine library: B. Wang, L. Chen, K. Kim, Tetrahedron Lett. 2001, 42, 1463.

[7] Sulfamate library: F. Albericio, L.M. Bryman, J. Garcia, E.L. Michelotti, E. Nicolas, C.M. Tice, J. Comb. Chem. 2001, 3, 290.

[8] Ugi multicomponent condensation library: Y.B. Kim, E.H. Choi, G. Keum, S.B. Kang, D.H. Lee, H.Y. Koh, Y. Kim, Org. Lett. 2001, 3, 4149.

[9] Thiohydantoin library: L. Ohberg, J. Westmann, J. Synlett 2001, 12, 1893.

[10] Bicyclic maleimide library: A.G.M. Barrett, R.J. Boffey, M.U. Frederiksen, C.G. Newton, R.S. Roberts, Tetrahedron Lett. 2001, 42, 5579.

[11] 4,6-Substituted pyrimidine library: G.M. Makara, W. Ewing, Y. Ma, E. Wintner, J. Org. Chem. 2001, 66, 5783.

[12] Piperazine benzamide library: E. Laborde, B.T. Peterson, L. Robinson, J. Comb. Chem. 2001, 3, 572.

[13] $\beta$-Turn peptidomimetic library: M. Eguchi, M.S. Lee, M. Stasiak, M. Kahn, Tetrahedron Lett. 2001, 42, 1237.

[14] N-Arylmaleimide library: H.R. Hoveyda, D.G. Hall, Org. Lett. 2001, 3, 3491.

[15] S. Chamoin, A. Jary, H.-J. Roth, manuscript in preparation.

[16] P. Quitt, J. Hellerbach, K. Vogler, Helv. Chim. Acta 1963, 32, 327.

[17] K.J. Shaw, J.R. Luly, H. Rapoport, H. J. Org. Chem. 1985, 50, 4515.

[18] C.M. Thompson, J.A. Frick, D.L.C. Green, J. Org. Chem. 1990, 55, 111 .

[19] A. Nefzi, J.M. Ostresh, R.A. Houghten, Tetrahedron Lett. 1997, 38, 4943.

[20] R.M. Freidinger, J.S. Hinkle, D.S. Perlow, B.-H. Arison, J. Org. Chem. 1983, 48, 77.

[21] K. Wisniewski, A.S. Kolodziejczyk, Tetrahedron Lett. 1997, 38, 483.
[22] T. Fukuyama, M. Cheung, C.-W. Jow, Z. Hidai, T. Kan, Tetrahedron Lett. 1997 38,5831 .

[23] J.H. Cho, B.M. Kim, Tetrahedron Lett 2002, 43, 1273 .

[24] G. Verardo, P. Geatti, E. Pol, A.G. Giumanini, Can. J. Chem. 2002, 80, 779 